\title{
Factors for Successful Use of Social Networking Sites in Higher Education
}

\author{
L Schlenkrich ${ }^{1}$, DA Sewry ${ }^{2}$ \\ Department of Information Systems, Rhodes University, South Africa.
}

\begin{abstract}
Social networking sites are extremely popular online destinations that offer users easy ways to build and maintain relationships with each other, and to disseminate information in an activity referred to as social networking. Students, lecturers, teachers, parents and businesses, in increasing numbers, use tools available on social networking sites to communicate with each other in a fast and costeffective manner. The use of social networking sites to support educational initiatives has received much attention. However, the full potential of social network sites has yet to be achieved as users continue to strive for optimal ways of using these sites, as well as battle to overcome the negative characteristics (for example, privacy, security, governance, user behaviour, information quality) of these sites. This paper proposes factors for successful use of social networking sites in higher educational institutions. These success factors need to be adopted by users in order to develop the positive aspects of social networking, while at the same time mitigating the negative characteristics. An initial set of factors for successful use of social networking sites, as well as measures to test successful use of social networking sites were derived from the literature. These factors were tested by means of an online survey of students at a university, the results of which informed the final factors for successful use of social networking sites. The factors enable users to overcome the negative characteristics associated with social networking sites. If used successfully, social networking sites can offer lecturers and students a useful tool with which to develop their relationship and contribute to their learning experience.
\end{abstract}

\section{CATEGORIES AND SUBJECT DESCRIPTORS}

H.3.5 [Information Storage and Retrieval]: Online Information Services - web-based services;

K.3.1 [Computers and Education]: Computer Uses in Education - collaborative learning.

\section{KEYWORDS}

Social Networking, Social Networking Sites, Education

\section{INTRODUCTION}

Social networking refers to the gathering, representation, processing and dissemination of social information, such as race, sexual orientation and partners, religion, body type, favourite books and movies, relationship status and photo albums [46]. This information is shared between friends, colleagues, family members and strangers [26]. Social networking is enabled via social networking sites (SNSs) predominantly, but not exclusively, on the Internet. Users register with a particular SNS, following which social interaction ensues. Social networking technologies are intended to be easy to learn and use [26], and consequently have been used in a variety of contexts to improve the speed and effectivity of communication.

Learning, as an intensely social activity [41], is one such context which can benefit specifically from the use of social networking. It provides opportunities for learning both within and without the classroom and increases the sense of connectedness between learners [26]. SNSs can be used to host events, debates, reviews; aggregate resources; support courses and reading circles; provide space for discussing ideas for learning design; expert elicitation and consultation as well as afford users opportunities for forging new connections and gaining access to "distributed intelligence" [12]. They have been used to solve assignment problems collaboratively [19] and craft an online identity [19]. Social networking also offers teachers and students opportunities to nurture the studentteacher relationship, which can ultimately create a positive learning experience for both parties [40]. However, the use of social networking in an educational context is not without concern.

Teachers with access to an extant, in-house secure site for information sharing and interaction with students are reluctant to change to popular SNSs, more so when they question their own technical competence with such sites [9]. Learners do not see the connection between use of social networking and skills valued by teachers at school [19]. Furthermore, the practice of sharing knowledge, what counts as knowledge in a learning community, learner characteristics and propensity to use social networking, technical problems (particularly for those who were not quite competent in technology), language barriers (particularly for those who were not English majors), and time management (particularly for those who were not familiar with blended e-learning) impede increased adoption of social networking in education [26].

Whilst acknowledging the value of social networking in education, it is not being used in its full capacity or to its fullest

\footnotetext{
${ }^{1}$ Email: lara.schlenkrich@bsg.co.za,

2 d.sewry@ru.ac.za
} 
potential [43, 48]. Further research is suggested in the areas of "cognitive and social processes through which students create, share and filter information" [48], as well as frameworks that describe patterns of user behaviour [12].

This research is concerned with the use of SNSs in an educational context and suggests factors for successful use of SNSs in higher educational institutions.

Section 2 provides a background to social networking. Section 3 explains the research methodology employed in the research. Section 4 describes the impact of social networking. Section 5 describes general guidelines for use of SNSs, whilst Section 6 proposes a set of factors for successful use of SNSs, as well as measures of successful use of SNSs derived from the literature. Section 7 describes the design of the experiment to test the proposed factors. Section 8 analyses the results of the experiment. Section 9 presents the final factors for successful use of SNSs and Section 10 concludes the work.

\section{BACKGROUND}

\subsection{Overview of social networking}

Boyd and Ellison [6] define SNSs as web-based services that allow users to construct a public profile within a bounded system, articulate a list of other users with whom they share a connection, and view and navigate through their list of connections and those made by others within the system.

A number of SNSs are available for use, each possessing a set of both common (to all SNSs) and specific functionality. Blogging [44] are online journals, published through the Web interface, and focused on topics reflecting the interests of the authors. Wikipedia [44] is an online open source encyclopedia built by aggregating wikis, which are tools of collaborative authoring of tagged hypertext content. Flickr [44] is an easy to use photo sharing service that allows users to upload, tag, and share photos. MySpace and Bebo [44] allows users to build, launch and share their multimedia Web presence, and invite friends to form social networks. Facebook [23] is a particularly popular online social networking community similar in functionality to MySpace and Bebo. LinkedIn [44] is a social network for business professionals. Del.icio.us [44] is a bookmarking service that allows users to create their tagged bookmarks in shared Web spaces. Blackboard/WebCT [5] is a learning management system that provides learners with opportunities to share comments and insights on particular aspects of courses with teachers and peers.

SNSs are extremely flexible to use and expand opportunities for socialisation [39]. They allow users to search for other students in their discipline, keep up with old friends and make new ones, flirt, gossip, complain about classes, and post an unlimited number of photos [39].

Social networking empowers users with low technological sophistication in using the Web to manifest their creativity, engage in social interaction, contribute their expertise, share content, and disseminate information and propaganda [44] or to network among business peers [51]. Social networking appeals to people because it is an opportunity for personal sharing of life experiences, venting frustrations and offering reflections on a variety of social issues [61].

Facebook is an extremely popular example of an SNS with a large following [36] which allows students to form study groups and find out about upcoming events in campus clubs and organisations [36]. Ellison et al [17] state that the site is tightly integrated with its users' daily media practices with typical users spending about twenty minutes a day on the site.

\subsection{Features on SNSs}

A common theme of social networking is the creation of a shareable personal profile [22]. Typically, users

1. Create a profile for themselves,

2. Connect with other users by sending a "friend" request, which needs to be accepted or denied,

3. Manage lists of friends, use a search engine to find them and invite them from their email accounts,

4. Send messages of various types (mostly email, but some sites use instant messaging as well),

5. Post photos in galleries, tag them, and share them with others, and

6. Customise a range of aspects, from layout and design, to function and selective disclosure of information to different audiences $[2,59]$.

\section{RESEARCH METHODOLOGY}

A quantitative research methodology using a positivist approach was adopted. The presence of a body of knowledge in the area of social networking that could be used to propose factors for successful use of SNSs argued for the use of the positivist approach. Quantitative research generally uses scientific methods, which include: the generation of models, theories and hypotheses; the development of instruments and methods for measurement; experimental control and manipulation of variables; collection of empirical data; modelling and analysis of data; and evaluation of results [30]. A key component of the analysis of the data includes factor analysis. Factor analysis is used extensively in social research to summarise data by identifying latent relationships within the data.

Steps in the research include:

1. An analysis of the social networking phenomenon, tools and underlying technology, common uses and impact of social networking.

2. An analysis of helpful hints and guidelines and success factors for effective social networking in organisations.

3. An analysis of the adoption of social networking in terms of the adoption of new technology and attitudes towards new technology.

4. Construction of an initial set of factors for successful use of SNSs.

5. Empirical investigation of the factors by means of a survey of students at a university.

6. An analysis of the results of the survey, followed by possible amendments to the factors.

7. Presentation of final factors for successful use of SNSs.

\section{IMPACT OF SOCIAL NETWORKING}

Social networking presents many opportunities, which may be exploited by institutions to enhance learning. However, many threats exist as well, which need to be overcome by institutions in order for the full potential of social networking to be realised.

\subsection{Positive Characteristics of Social Networking: General}

- Rich environment for content. Social networking tools allow users to create a reasonably accurate and dynamic information space [44], in which content and applications can be stored that may span a wide spectrum inclusive of email, pictures, journal entries, music, video, contacts, calendar, spreadsheets, bookmarks, chat transcripts, location information, and work-related content. 
- Reputation systems control negative behaviour. Reputation systems are at the centre of SNSs. They instil confidence in the social environment in which individuals engage bringing legitimacy and context to the interactions in these environments [49]. They also improve governance of SNSs by restraining negative behaviour [37]. Users of these sites are aware that their actions are monitored (by peers and administrators), and try to behave in an appropriate manner.

- Weak ties enable a range of opinions. Contact through SNSs are often shallow, but these "weak ties" (weak relationships) are usually enough to encourage unanticipated exchanges [37]. Mann [37] believes that weak links can have more influence over decisions and insights than strong links because there are usually so many more of them. These links allow workers to have interactions with a wider variety of other colleagues, providing exposure to many more groups.

- Provides a solution to the "Knowledge Gap". The knowledge gap is the general lack of content sources for the period between when news is published and the history books are written [32]. Web logs and wikis fill this knowledge gap, acting as constantly updated secondary sources of knowledge [32].

- Social networking delivers value. Many small and large organisations use blogs for marketing and public relations purposes, as well as for internal communication, collaboration, and knowledge sharing and management [61]. They also stimulate creative thinking [54] and serve as a source for quick answers [56]. Real-time access to a community or network of experts can create real efficiencies and speed up processes as organisations benefit from the shared knowledge that their employees gain from these networks $[1,35,50]$.

- Improving Customer Relationship Management. Salespeople tend to carry relationships from one company to another [14]. It is in a company's best interests to integrate a social networking platform with a sales force automation application. This improves salespersons' effectiveness, and may enrich relationship knowledge about customers and prospects [14].

- Enables effective Project Management. Where people are separated by time or distance, blogs and associated technologies have the potential to weld teams and communities of practice together, introduce new team members, side-step the hierarchy, dramatically reduce email, put control of communications into the hands of its participants and allow project heads to keep team members informed of news and progress, as well as observe reactions from comments posted on the site [55]. SNSs also facilitate finding co-workers with particular skills or discovering past work experiences that might be relevant to new projects [15].

- Transforms the Knowledge Management Paradigm. Social networking taps into networks of people to access relevant practical expertise at the moment of need [27]. Social networking arises spontaneously as a core activity of daily work and is driven by natural motivations because it lets people share what they want to know, whenever they want to, with whomever and in whatever form they want [27]. People are able to choose how they want to manage their own personal knowledge, and embrace the tools that serve their purpose best [27].

- Increased productivity and reduced cost. Facebook allows employees to communicate with co-workers and colleagues in seconds, leaving more time for productive work [37]. Mann [37] also states that managers around the world are using Facebook to track their colleagues' projects and activities; they can see what people are working on immediately, without having to call or email them. Companies are also using Facebook to collect and test ideas about product development with potential customers, or as a sales tool to identify and find out about contacts at a target company [37].

\subsection{Positive Characteristics of Social Networking: Educational}

- Fosters communication and collaboration. Blogging represents a growing activity among professionals and students who appreciate blogs for their mix of informal commentary, links to resources and personal touch [61]. SNSs offer people opportunities to share life experiences, vent frustrations, offer reflections on social issues and express themselves in a non-threatening atmosphere [61]. SNSs also enable community involvement in locating expertise, sharing content and collaborating to build content [7], and allow knowledge workers to extend the range and scope of their professional relationships [45].

- Social networking supports Research and Development $(R \& D)$. Researchers create new knowledge while using existing knowledge [47]. Their activities often take place in a social context made up of informal exchanges, brainstorming, idea exploration and cross-fertilisation. Social networking allows researchers to draw from a social network of information and people outside of their traditional "circle of friends".

- Social networking promotes accumulation of social capital. Social capital, resources accumulated through relationships among people [17], has been linked to positive social outcomes, including: better public health, lower crime rates, and more efficient financial markets [17]. Facebook lowers the barriers to participation so that students who might otherwise shy away from initiating communication or responding to others are encouraged to do so, and, amongst highly-engaged users, strengthens relationships that would otherwise remain weak [17].

- Motivation and Learning Opportunities. [10] believes that classroom blogging has the potential to motivate students, to build online collaboration, and enhance learning opportunities. Literacy in the classroom may be promoted through the use of storytelling and dialogue [10]. Clyde [10] describes SNSs as educational tools because they allow students to develop ideas and invite feedback. Social networking helps teachers promote reflective analysis and the emergence of a learning community that goes beyond the school walls [10]. Mazer et al [40] found that participants who accessed the Facebook website of a teacher who disclosed large amounts of information, anticipated higher levels of motivation and affective learning, indicating positive attitudes toward the course and the teacher. Teachers who personalise teaching through the use of humour, stories, enthusiasm, and self-disclosure not only are perceived by their students to be effective in explaining course content [40], but create a positive teaching atmosphere. Social networking also offers educators an excellent platform to forge their own professional identity by sharing with other colleagues and debating ideas [61], allowing them to extend their professional relationships.

- Learning Tool in Libraries. Clyde believes that blogging in schools is an information-related activity that requires and develops information skills in students and should therefore be supported by school libraries. Social networking can be used by librarians to raise their visibility, augment or eliminate stereotypical images of librarians, increase 
research assistance traffic via Facebook message boxes and make library services and librarian assistance more convenient [36].

- Enables Educators to be Better Advisors. Comments that students post on the site may provoke thoughtful conversation [33]. SNSs may provide helpful information to educators and help them deal with certain situations better; one educator knew to go easy on a student when he saw his status change from "in a relationship" to "single" [33]. Students may also feel more comfortable approaching educators who are present and friendly or who interact casually with them on Facebook; it gives students the encouragement they need [33].

- Digital Learning as a Substitution Process. Online learning is a new social process that is beginning to act as a complete substitute for both distance learning and the traditional faceto-face class [24]. The believe that face-to-face courses, blended with online learning technologies and methodologies, are generally rated by students as significant improvements over face-to-face (only) classes.

\subsection{Weaknesses and Threats of Social Networking}

- Lack of privacy and the related security risks. Private information, typically the user profile, posted on an SNS is often violated [25, 34]. Although mechanisms are available to limit privacy violations, not all sites offer such mechanisms, and, if they are, they are not always/consistently used by users [6]. Access to various pieces/levels of information is at the discretion of users, should they know about or elect to adopt associated protection mechanisms [59]. Despite a manifest need for explicit privacy policies and data protection mechanisms, privacy within SNSs is often not expected or is undefined [16] or difficult to find and interpret [31]. Trust too may affect what users are willing to share on sites - Facebook users are more willing to share information, due to a greater degree of trust in the network, than MySpace users [6].

- Social and network security. SNSs are easy to join, lack basic security measures and are easy for third parties to access [20,44]. Risks include identity theft, online and physical stalking, embarrassment, price discrimination [20], as wells as fraudulent profile pages and messages, defamation, and theft of artwork or intellectual property [60]. The safety of young users is also a primary concern as sexual predators attempt to make contact with unsuspecting teenagers $[6,16]$. Internet predators and cyberbullying are also features of SNS use [28, 34].

- Legal and regulatory matters. SNSs can be used to perform a variety of activities that would be considered illegal in many jurisdictions [60], for example, online bullying, theft of intellectual property, identity fraud, defamation of character, privacy infringement and slander. Unfortunately, much established law and regulation does not apply to SNS.

- Suspect information quality. Not all weblogs carry reliable, current information [10]. Some weblogs are created for the sole purpose of providing an online platform for the views, rantings and creative works of the blogger [10]. Desisto and Smith [14] believe that this will be less of an issue for experienced users, but insist that new users be educated on information reliability and quality.

- Managing Personal and Professional Time. Social networking can impact student productivity and work/life balance [7]. Teachers and lecturers are often distressed by the lack of concentration and interest displayed by students who have constant access to these SNSs. Many organisations are concerned with managing productivity in more loosely structured network environments, especially in organisations where the nature of their work is not collaborative or their cultural environment does not recognise the importance of social interactions [7]. Social computing holds tremendous disruptive potential for organisations.

- Governing participant behaviours. Bradley [7] explains that governance of SNSs is not a "one size fits all" proposition, but depends on who is participating (employee or public), how they are participating (business or personal) and where they are participating (corporate site or public site). Social applications, like all social structures, contain bad behaviour, which should be expected and addressed in application design and social mediation [7]. Organisations must balance the benefits of social networking with the risks of bad behaviour.

- Cultural barriers. Social networking is unlikely to work in organisations with a strong "command-and-control" culture [55]. These traditional, hierarchical organisations will feel threatened by the amount of trust and equality that is required in order for social networking to be effective [55]. Social networking holds the potential to destroy hierarchies and departments [57]. Barriers can also form between cultures inclined towards technology and those that battle to adopt new technologies.

- Lack of Professionalism. Students post information that they do not necessarily want their professors to see [23]. Students indicate that the student/faculty relationship should remain professional and should not be sociable. Teachers' own credibility might also be at stake depending on their profile content and their in/ability to control profile content [40]. Mazer et al [40] urge teachers to proceed with caution in their use of SNSs.

- General reasons why organisations reject social networking. Managers increasingly reject social networking in their organisations because of a loss of control; leakage of information; difficulty in placing so much trust in employees; limited direct benefit; possible embarrassing exposure; potential to bypass "official channels"; threat to conventional power structures; and reduction of employee productivity [56]. Organisations that engage in social networking risk market collisions, product dead ends and paralysis through lawsuits, "social pollution" such as spam, scams, stalkers, identity theft and display of objectionable content. Demographic collisions can also occur between older professionals who do not realise the value of social networking (or are uncomfortable using the tools) and younger employees whom they think are wasting time [59].

- Use of SNSs by employers/professors to check up on Potential Employees/students. Despite social contracts describing acceptable behaviour and imploring only personal use of information on SNSs [51], recruiting companies continue to use such information in employment decisions [46] raising a host of ethical concerns [51].

\section{GENERAL GUIDELINES FOR USE OF SNSS}

Social networking presents a wealth of opportunities for users within a social, educational and business setting. Unfortunately, they simultaneously also demonstrate a number of weaknesses and can be a threat to organisations and users. Guidelines for good use of SNSs are necessary and span a wide variety of areas of concern.

Policies and standards must be in place in order to manage security risks in social networking [60]. Such a governance 
programme (policies and standards) should include attention to matters of accountability for own profile, appropriate and professional content, appropriate use of profile that distinguishes between personal and professional use and information ownership, professional vs personal messaging and monitoring of profile content $[42,60]$.

Regulations applicable to non-social network information should also apply to any activities that take place in the social network environment. Walls [60] states that corporations should manage content and staff behaviour on SNSs in a similar way to other environments. Social contracts found on SNSs outline acceptable behaviour and posting rules [51]. If these social contracts are violated, the administrators of the SNS site may remove the offending person's account from the site, as well as ban them from using the site in future [18]. If an illegal violation takes place, the perpetrator may be prosecuted either by the SNS or by the individual whose rights were violated [18]. Social contracts should be followed by users in order to prevent privacy, security, legal and personal problems from occurring on SNSs. Appropriate use of social contracts will enable users to keep the overlap between their personal and professional lives to a minimum [51].

It is possible to collect a wide range of content about individuals for use in recruitment or promotions. Walls [60] urges users not to use this information, as many fraudulent profiles have been constructed containing incorrect and private information without the knowledge of the targeted people. It is further suggested that actionable information should be checked carefully before making any decisions based on this information.

Mazer et al [40] suggest that teachers should be professional, be themselves and respect their students' privacy in order to increase student motivation, encourage affective learning and improve classroom climate. Krieglstein [29] suggests that official course activities be constrained to official online tools, whilst Berg et al [3] are of the opinion that SNSs should be left for students as a fun site. Timely advice is provided by Lipka [33] who states that the consensus on "friending" on SNSs seems to be: accept students' requests, but do not initiate any yourself.

Not all persons and cultures are equally comfortable communicating on SNSs. Teachers should prepare children for the media-saturated culture by developing coping techniques and practicing responses to problematic situations [4].

In addition to general guidelines, models have been developed for the adoption of Information Systems applications, like email and the Internet, which can be applied equally to the adoption of social networking [53]. The extent to which critical thinking skills are developed, so espoused by the Constructivist Approach to teaching and learning [11], also impacts the adoption of social networking. Additional factors affecting the adoption and use of SNSs include: age of the user [13]; level of education of the user [13, 28], experience (computer literacy skills) of the user $[8,13,38]$, etiquette of the user [58], cognitive ability of the user [13], training of the user $[8,13]$, attitude towards application of the user [8], and level of access (broadband) available to the user [38].

\section{PROPOSED FACTORS FOR SUCCESSFUL USE OF SNSS}

A number of factors are hypothesised to influence the successful use of SNSs (independent variables). These factors (see Table 1) comprise guidelines (both for features of SNSs and for user behavior) that promote successful use of SNSs between students and teachers/lecturers, students and students, and teachers and teachers.
Table 1. Factors (Guidelines) for Successful Use of SNSs

Factor (Guideline), References and Description (Items)

- Privacy and Security Measures [29, 42, 60]

Appropriate privacy and security measures should be taken to protect personal information

- Legal and Acceptable Activities [16,18, 29, 51]

Legal and acceptable activities should be practiced at all times

- Suspect Information [60]

The reliability of information posted on SNSs should be analysed

- Personal and Professional Time [7] Personal and professional use of SNSs, as well as associated information, should be separated

- Types of Adopters [4, 53] Patience and understanding of various types of technology adopters (cultures) should be exercised

- Professional and Ethical Behaviour [18, 29, 33, 40] Professional and ethical behavior should be practiced

- Technical Experience (Computer Literacy) $[8,13]$ Computer Literacy courses should be taken to become technically proficient and comfortable with SNS applications

- Positive Attitude [8]

SNSs should be fun and exciting to use for extended periods of time

- Technical Capacity (Level of Access) [38] Fast internet links should be used to access SNSs to facilitate large volumes of information transfer

- Ease of Use [26] SNSs should be easy to use

- Functionality [6] SNSs should provide users with a wide-range of features and functionality

- Current Issues [61] Current issues should be discovered and discussed

- Controversial Issues [61]

Controversial issues should be discovered and discussed

In turn, successful use of SNSs (dependent variable) is measured by a number of factors (see Table 2).

A number of hypotheses are defined, one for each factor (guideline) for successful use of SNSs (see Table 3).

\section{DESIGN OF THE EXPERIMENT}

An empirical study tested the factors for successful use of SNSs within the context of student use of Facebook at a university. Facebook is a particularly popular SNS amongst students and represents a rich source of information on use of an SNS.

\subsection{Data-Gathering Tool}

A questionnaire was developed that was structured around the hypotheses which, in turn, were based on the factors (independent variables) that are hypothesised to influence successful use of SNSs and the factors (dependent variables) used to measure successful use of SNSs.

The questionnaire was in two parts: Part 1 required respondents to provide information related to respondent demographics, actual number of Facebook friends, and actual number of hours spent using Facebook. Part 2 comprised a series of Lickert Scale (5-point scale expressing a level of likelihood, competence or agreement) questions (developed 
Table 2. Factors (Measures) of Successful Use of SNSs

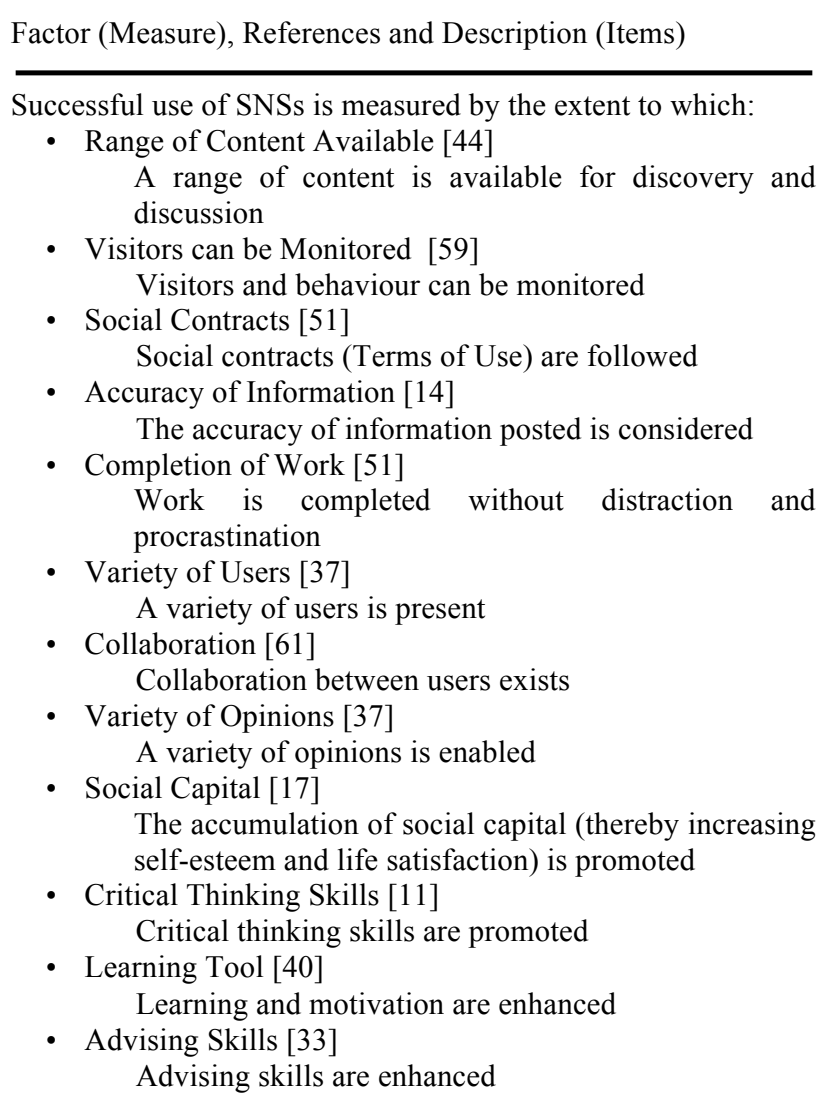

from the items of which each factor comprises) related to information displayed on profile, people viewing profile, uses of Facebook, security measures, application competency, and various other factors affecting successful use of SNSs, and measures of successful use of SNSs. No open-ended questions were used.

\subsection{Online Questionnaire}

The online questionnaire was loaded onto the university's learning management system available for access by all registered students. An advertisement for the questionnaire was put on the main page with a link to the questionnaire. Any interested student was able to "self-select" the questionnaire for completion and do so anonymously. The survey was open for a period of one week.

\section{ANALYSIS OF RESULTS}

The survey attracted 599 student respondents, twelve of whom were not members of Facebook, rendering 587 useable, completed questionnaires.

The results were notable for a dominance of female respondents (see Figure 1), a majority of students in the age group 18-20 year old (see Figure 2), a similar number of black and white respondents who comprised a significant majority of the respondents (see Figure 3), and a majority of first year students (see Figure 4) all of which were consistent with the gender, age, demographic and academic status distribution of students at the university. The results were also notable for an overwhelming number of students who use their own computer (see Figure 5), a generous spread of number of Facebook friends from $50-400$ (see Figure 6), and use of Facebook of an hour at weekends (see Figure 7) and half an hour during the week (see Figure 8).
Table 3. Hypotheses

\section{Hypothesis}

- H1: Implementing appropriate privacy and security measures is associated with successful use of SNSs

- H2: Practicing legal and acceptable activities on SNSs is associated with successful use of SNSs

- H3: Analysing suspect information found on SNSs before use is associated with successful use of SNSs

- H4: Managing personal and professional time is associated with successful use of SNSs

- H5: Understanding and being patient with various types of technology adopters (cultures) is associated with successful use of SNSs

- H6: Professional and ethical behaviour is associated with successful use of SNSs

- H7: Technical experience (computer literacy) is associated with successful use of SNSs

- H8: Positive attitude is associated with successful use of SNSs

- H9: Technical capacity (level of access) is associated with successful use of SNSs

- H10: Ease of use is associated with successful use of SNSs

- H11: Functionality is associated with successful use of SNSs

- H12: Discovering and discussing current issues is associated with successful use of SNSs

- H13: Discovering and discussing controversial issues is associated with successful use of SNSs

Further analysis indicates that:

- Information displayed on Facebook profiles. Students are likely to display their sexual orientation, their high school, their likes and dislikes, photos, their birthday and their relationship status, while they were ambivalent about displaying their contact details, their classes, their work information and their sport information.

- Viewers of Facebook profiles. Students think it is very likely that their friends are viewing their profiles; they think it is likely that family and friends-of-friends are viewing their profiles; they are unsure whether strangers view their profiles; and they think it is unlikely that wardens, lecturers, employers and police view their profiles.

- Uses of Facebook. Students are very likely to use Facebook to keep in touch with old school friends; they are likely to use Facebook to check out someone they met socially and learn about people they are interested in; they are ambivalent about using Facebook to find out about people in their classes, find out about people living near them and to organise team meetings; and they are unlikely to use Facebook to meet new people, learn about their lecturers and to find out about university assignments.

- Security precautions. Students take security precautions so that only friends can see their profile and contact information; they are unsure whether friends-of-friends, people in their networks and people in their groups can see their profile information; and they think it is unlikely that anyone can see their profile. Furthermore, it is likely that they customise their contact information. 


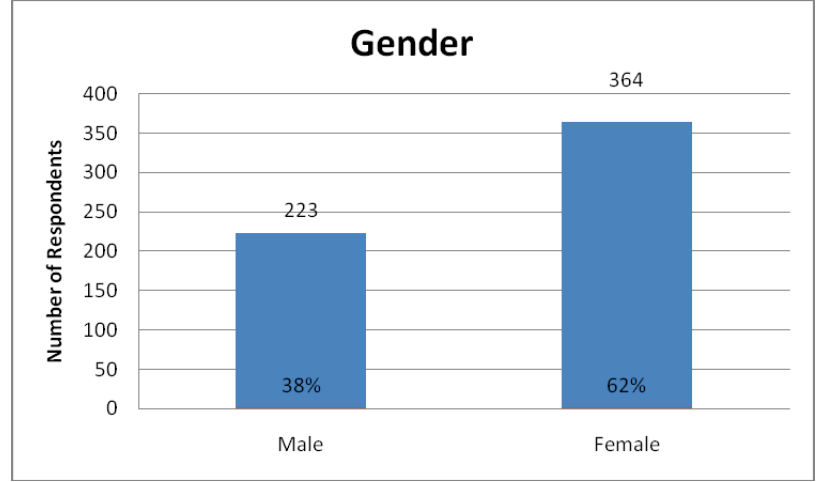

Figure 1. Gender Analysis

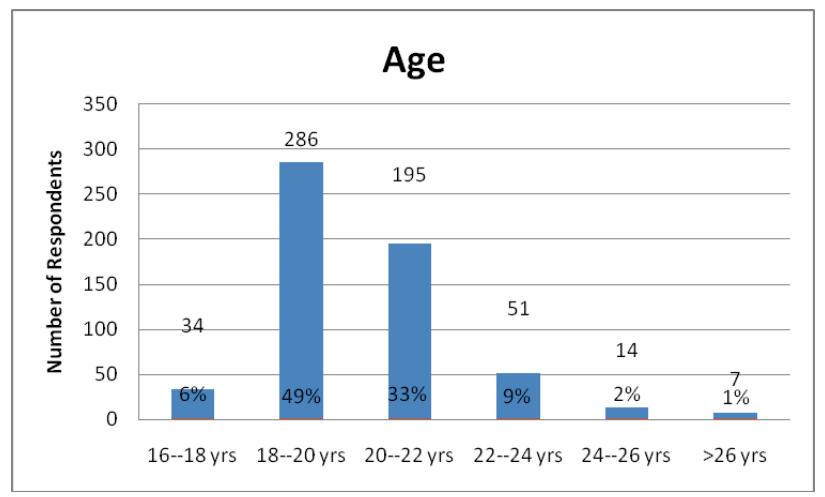

Figure 2. Age Analysis

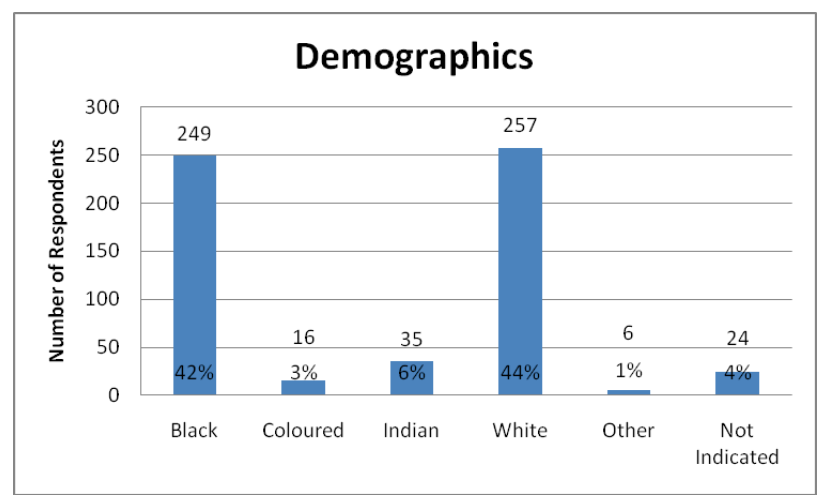

Figure 3. Demographic Analysis

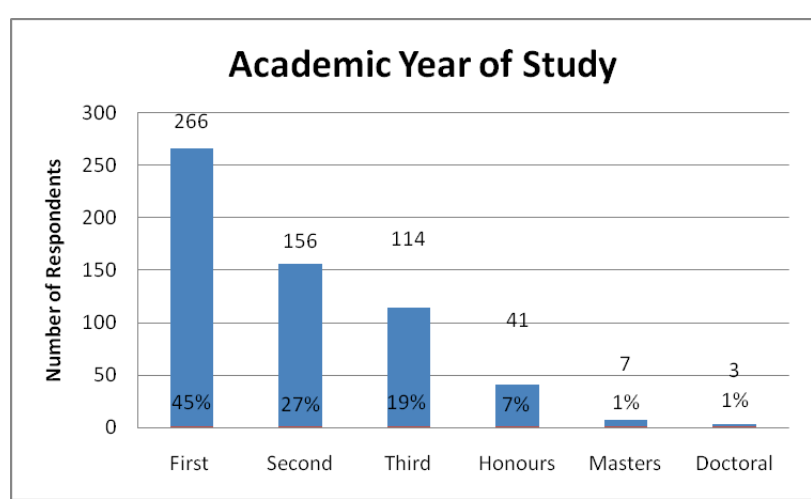

Figure 4. Academic Year of Study Analysis

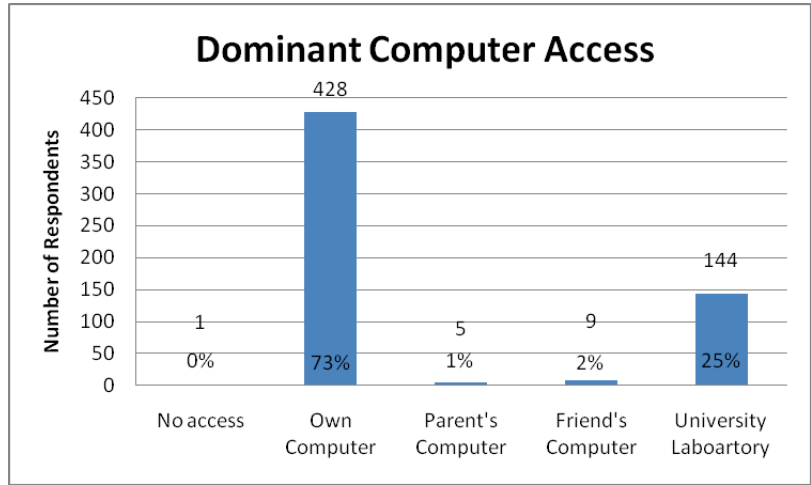

Figure 5. Dominant Computer Access Analysis

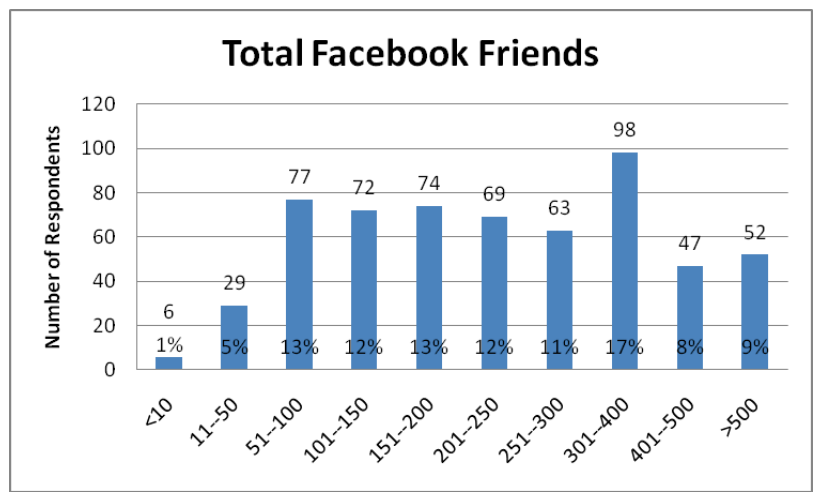

Figure 6. Total Facebook Friends Analysis

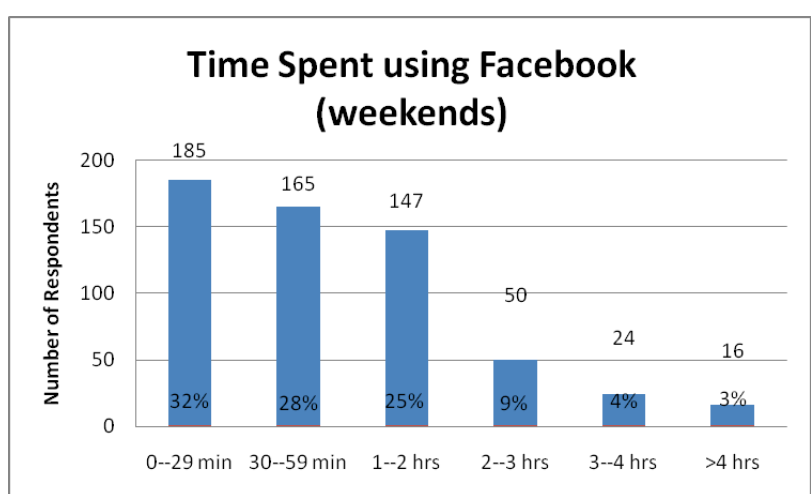

Figure 7. Time Spent using Facebook (weekends) Analysis

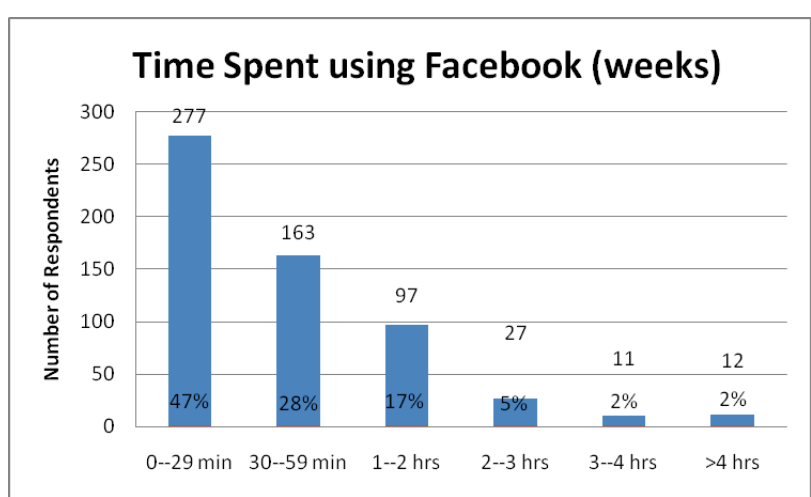

Figure 8. Time Spent using Facebook (weeks) Analysis 
Table 4. Factor Analysis: Independent Variables

\begin{tabular}{|c|c|c|c|}
\hline \multirow{2}{*}{$\begin{array}{l}\text { Factor } \\
\text { Item }\end{array}$} & \multicolumn{2}{|r|}{ Factor } & \multirow[b]{2}{*}{ Loading } \\
\hline & Loading & Item & \\
\hline \multicolumn{2}{|l|}{ Privacy and Security Measures (Settings for Protection): } & \multicolumn{2}{|l|}{ Professional and Ethical Behaviour (Content): } \\
\hline 'Friends-of-friends can see my profile' & 0.737110 & 'My high school name is posted' & 0.538963 \\
\hline 'People in networks can see my profile' & 0.752584 & 'My class names are posted' & 0.660505 \\
\hline 'People in groups can see my profile' & 0.749086 & 'My likes and dislikes are posted' & 0.670038 \\
\hline 'Anyone can see my profile' & 0.737037 & 'My work information is posted' & 0.693535 \\
\hline 'Friends-of-friends can see my contact information' & 0.676961 & 'Photos of myself and others are posted' & 0.258798 \\
\hline \multicolumn{2}{|c|}{ Privacy and Security Measures (Viewers of Profile): } & 'My relationship status is posted' & 0.333916 \\
\hline 'Family view my profile' & 0.248925 & 'My birthday is posted' & 0.342462 \\
\hline 'Friends-of-friends view my profile' & 0.238661 & 'My Sport information is posted' & 0.594846 \\
\hline 'Strangers view my profile' & 0.375395 & \multicolumn{2}{|l|}{ Professional and Ethical Behaviour (Behaviour): } \\
\hline 'Wardens view my profile' & 0.740834 & 'Total number of Facebook friends' & 0.503552 \\
\hline 'Lecturers view my profile' & 0.839810 & 'I swear when writing Facebook messages' & 0.622770 \\
\hline 'Employers view my profile' & 0.752913 & 'I post or comment on photos of bad behaviour' & 0.562460 \\
\hline 'Police view my profile' & 0.748292 & \multicolumn{2}{|l|}{ Technical Experience (Computer Literacy Skills): } \\
\hline \multicolumn{2}{|l|}{ Legal and Acceptable Activities: } & 'Competence in use of email' & 0.837473 \\
\hline 'Check out someone I met socially' & 0.455067 & 'Competence in use of the Internet' & 0.852099 \\
\hline 'Meet new people' & 0.632693 & 'Competence in use of a word processor' & 0.854324 \\
\hline 'Learn more about people in classes' & 0.739633 & 'Competence in use of a spreadsheet' & 0.749788 \\
\hline 'Learn more about people living near me' & 0.763874 & 'Competence in use of a DBMS' & 0.534232 \\
\hline 'Check out someone I am interested in' & 0.572391 & 'Competence in use of instant messaging' & 0.799998 \\
\hline 'Learn more about my lecturers' & 0.444000 & 'Competence in use of SNSs' & 0.745574 \\
\hline 'Find out about university assignments' & 0.388449 & \multicolumn{2}{|l|}{ Positive Attitude: } \\
\hline 'Organise team meetings' & 0.256347 & 'Weekend hours spent using Facebook' & 0.720847 \\
\hline 'Change Facebook to suit personality' & 0.301065 & 'Week hours spent using Facebook' & 0.742669 \\
\hline 'Specific version of Facebook to match culture' & 0.265159 & 'Use Facebook during work hours' & 0.430911 \\
\hline \multicolumn{2}{|l|}{ Suspect Information: } & 'Use Facebook a large part of week' & 0.776134 \\
\hline 'No one can see contact information' & 0.220828 & 'Use Facebook a large part of weekend' & 0.752177 \\
\hline 'Customise contact information for friends' & 0.233983 & 'Volume of information uploaded and downloaded' & 0.485134 \\
\hline 'Consider effects of personal postings' & 0.696076 & \multicolumn{2}{|l|}{ Usability: } \\
\hline 'Check information before posting' & 0.700580 & 'Comfortable using all Facebook applications' & 0.483141 \\
\hline 'Check everything found on Facebook' & 0.515901 & 'Facebook is fun to use' & 0.584768 \\
\hline \multicolumn{2}{|l|}{ Personal and Professional Time: } & 'Facebook is exciting to use' & 0.555982 \\
\hline 'Only friends can see contact information' & 0.363591 & 'My Internet connection is fast' & 0.192490 \\
\hline 'Personal information is safe' & 0.397310 & 'Facebook is easy to use' & 0.639706 \\
\hline 'Not necessary to check information' & 0.586132 & 'Facebook took a short time to learn' & 0.642540 \\
\hline 'Personal and academic contacts are the same' & 0.519203 & 'Facebook incorporates new and useful features' & 0.690432 \\
\hline & & 'Facebook makes it easy to reach people' & 0.646777 \\
\hline & & \multicolumn{2}{|l|}{ Current and Controversial Issues: } \\
\hline & & 'I use Facebook to discuss current issues' & 0.778545 \\
\hline & & 'I use Facebook to discover current issues' & 0.807878 \\
\hline & & 'I use Facebook to discuss controversial issues' & 0.867492 \\
\hline & & 'I use Facebook to discover controversial issues' & 0.849111 \\
\hline
\end{tabular}

- Application competency. Students are highly competent using email, the Internet and word processors; they are competent using spreadsheets, instant messaging applications and social network sites; and they are ambivalent about using database management systems.

\subsection{Factor Analysis}

Exploratory factor analysis was performed on both the independent and dependent variables (each of which comprised a number of factors and, in turn, items) to summarise the original items based on their underlying patterns. Factors were extracted using maximum likelihood analysis (an analysis in which, for a fixed set of data and underlying model, values of the model parameters are selected that produce a distribution that gives the observed data the greatest probability), and a varimax normalised rotation (to maximize the variance of the "new" factor, while minimizing the variance around the new factor) was undertaken to allow for inter-correlation between the factors [52]. The majority of the items loaded higher than 0.35 on any factor; any items loading below this value were considered, but were not given as much weight as the higher factor loadings. It should be noted that factor loadings of \pm 0.30 are considered to meet minimal requirements (especially with a sample size of greater than 350), whilst loadings of \pm 0.40 are considered more important and loadings of \pm 0.50 or greater are considered practically significant [21].

\section{Independent variables}

The factor analysis reduced the number of factors on which items loaded from thirteen to eleven (see Table 4 for revised factors). Notable features of the analysis included:

- Items expected to load on Privacy and Security Measures, loaded onto two new factors, namely Privacy and Security Measures (Settings for Protection) describing whom is enabled to view information and Privacy and Security Measures (Viewers of Profile) describing who is likely to view information. 
- Items expected to load on Professional and Ethical Behaviour loaded onto two new factors, namely Professional and Ethical Behaviour (Content of Profile) describing the content of the profile and Professional and Ethical Behaviour (Behaviour) describing behaviour. Interestingly, the item indicating the total number of Facebook friends loaded on Professional and Ethical Behaviour (Behaviour) as well.

- Items expected to load on Legal and Acceptable Activities and Types of Adopters load onto an expanded Legal and Acceptable Activities. Items relating to changing Facebook to suit user personality and having Facebook match user culture influences the nature of activities performed.

- An item related to the use of Facebook during work hours expected to load on Personal and Professional Time loaded instead on Positive Attitude. Mere use of Facebook is regarded positively regardless of when.

- Items expected to load on Technical Capacity (Level of Access), Ease of Use, Functionality and Positive Attitude loaded collectively on a new factor, namely Usability. Additionally, an item related to the level of comfortableness with using Facebook applications also loaded on the new factor, Usability.

- Items expected to load individually on Current Issues and Controversial Issues both loaded on a new factor, namely Current and Controversial Issues. No distinction was seen between current and controversial issues.

\section{Dependent variables}

The factor analysis reduced the number of factors on which items loaded from twelve to ten (see Table 5 for revised factors). Notable features of the analysis included:

- Items expected to load on Range of Content Available is split into two new factors, namely Range of Content (Content for viewing) describing actual content available and actions for content made available and Range of Content (Viewers of content) describing who might view what content.

- Items expected to load individually on Visitors can be Monitored and Range of Content is Available loaded on a new factor Visitor Behaviour.

- Items expected to load individually on Accuracy of Information and Critical Thinking Skills loaded on a new factor Critical Thinking and Information. Additionally, an item relating to the ease of class participation given greater knowledge of lecturers also loaded on the new factor, Critical Thinking and Information.

- Items expected to load individually on Learning Tool and Advising Skills both loaded on a new factor Learning Tool and Advising Skills. Facebook as a learning tool and a tool for improved advice are not seen as distinct.

- Items expected to load individually on Variety of Opinion and Collaboration both loaded on a new factor Collaboration and Variety of Opinion. Working together and increased opinions go hand in hand.

Table 5. Factor Analysis: Dependent Variable

\begin{tabular}{|c|c|c|c|}
\hline \multirow{2}{*}{$\begin{array}{c}\text { Factor } \\
\text { Item }\end{array}$} & \multicolumn{2}{|r|}{ Factor } & \multirow[b]{2}{*}{ Loading } \\
\hline & Loading & Item & \\
\hline Range of Content (Content for Viewing): & & Learning Tool and Advising Skills: & \\
\hline 'Reprimanded for content on my profile' & 0.512389 & 'Easier interaction with better knowledge of peers' & 0.605241 \\
\hline 'Variety of content is displayed on my profile' & 0.718982 & 'Convenience of library messages sent via Facebook' & 0.781591 \\
\hline Range of Content (Viewers of Content): & & 'Improved use of library by use of Facebook' & 0.769078 \\
\hline 'I mind if prospective employers check my profile' & 0.634578 & 'Approachability of lecturer with Facebook profile' & 0.759037 \\
\hline 'Facebook used to check out people I'm interested in' & 0.571590 & 'Comfort with lecturers viewing my profile' & 0.573571 \\
\hline Visitor Behaviour: & & 'Lecturers who know students as better advisors' & 0.618025 \\
\hline 'I have been de-friended' & 0.640740 & Social Capital: & \\
\hline 'I stalk people on Facebook for fun' & 0.679909 & 'If Facebook not used, I feel out of touch' & 0.654713 \\
\hline 'Unwanted visitors look at my profile' & 0.447253 & 'Facebook makes me feel part of community' & 0.771542 \\
\hline 'I look at strangers' profiles' ' & 0.640597 & 'Use of Facebook makes me feel satisfied with life' & 0.743969 \\
\hline Social Contracts: & & 'Facebook suits my personality and culture' & 0.378994 \\
\hline 'I know about Terms of Use of Facebook' & 0.884619 & Variety of Users: & \\
\hline 'I follow the Terms of Use of Facebook' & 0.857019 & 'Use Facebook for same reasons as friends' & 0.688734 \\
\hline Completion of Work: & & 'Use Facebook differently to friends' & -0.789801 \\
\hline 'Facebook distracts me from my work' & 0.786143 & Collaboration and Variety of Opinion: & \\
\hline 'Facebook is a vehicle for procrastination' & 0.762842 & 'Use Facebook to contact team members' & 0.578446 \\
\hline Critical Thinking and Information: & & ‘Easy to reach people using Facebook’ & 0.722668 \\
\hline 'I believe information on Facebook' & 0.500363 & 'Informal exchanges promote broader perspectives' & 0.605005 \\
\hline 'I have been misled by information on Facebook' & 0.442624 & 'Offering of opinions on current/controversial issues' & 0.436698 \\
\hline 'Use of abstract thinking and problem solving' & 0.540034 & & \\
\hline 'Need for concentration when using Facebook' & 0.772080 & & \\
\hline 'Easier class participation with knowledge of lecturer' & 0.687399 & & \\
\hline
\end{tabular}




\subsection{Hypothesis Testing}

A number of hypotheses were defined on the factors for successful use of SNSs (see Table 3). The above factor analysis resulted in a revised set of hypotheses (see Table 6).

The revised hypotheses were then analysed using Pearson's Correlation Coefficient which determines the extent to which values of two aggregate scales are proportional to each other [52]. The hypotheses tests attempt to demonstrate relationships between the factors and the dependent variable: successful use of SNSs. A confidence level of $95.5 \%(\mathrm{p}<$ $0.05)$ was set. The results are contained in Table 7.

The results of the tests of the hypotheses indicate the following:

- A relationship exists between Privacy and Security Measures (Settings for Protection) and successful use of SNSs. The correlation level is medium, meaning that the settings instituted do influence the successful use of SNSs.

- A relationship exists between Privacy and Security Measures (Viewers of Profile) and successful use of SNSs. The correlation level is, however, small, meaning that who views people's profile does not influence greatly the successful use of SNSs.

- A relationship exists between Legal and Acceptable Activities and successful use of SNSs. The correlation level is medium, meaning that activities on SNSs do influence the successful use of SNSs.
Table 6. Revised Hypotheses

\begin{tabular}{|c|c|}
\hline \multicolumn{2}{|l|}{ Hypothesis } \\
\hline - H1: & $\begin{array}{l}\text { Implementing appropriate privacy and security } \\
\text { measures (settings for protection) is associated } \\
\text { with successful use of SNSs }\end{array}$ \\
\hline - $\mathrm{H} 2$ : & $\begin{array}{l}\text { Implementing appropriate privacy and security } \\
\text { measures (viewers of profile) is associated with } \\
\text { successful use of SNSs }\end{array}$ \\
\hline - H3: & $\begin{array}{l}\text { Practicing legal and acceptable activities on } \\
\text { SNSs is associated with successful use of SNSs }\end{array}$ \\
\hline - $\mathrm{H} 4:$ & $\begin{array}{l}\text { Analysing suspect information found on SNSs } \\
\text { before use is associated with successful use of } \\
\text { SNSs }\end{array}$ \\
\hline - $\mathrm{H} 5:$ & $\begin{array}{l}\text { Managing personal and professional time is } \\
\text { associated with successful use of SNSs }\end{array}$ \\
\hline - H6: & $\begin{array}{l}\text { Professional and ethical behaviour (content) is } \\
\text { associated with successful use of SNSs }\end{array}$ \\
\hline - $\mathrm{H} 7$ : & $\begin{array}{l}\text { Professional and ethical behaviour (behaviour) } \\
\text { is associated with successful use of SNSs }\end{array}$ \\
\hline - H8: & $\begin{array}{l}\text { Technical experience (computer literacy) is } \\
\text { associated with successful use of SNSs }\end{array}$ \\
\hline - H9: & $\begin{array}{l}\text { Positive attitude is associated with successful } \\
\text { use of SNSs }\end{array}$ \\
\hline - H10: & $\begin{array}{l}\text { Usability is associated with successful use of } \\
\text { SNSs }\end{array}$ \\
\hline - H11: & $\begin{array}{l}\text { Discovering and discussing current and } \\
\text { controversial issues is associated with successful } \\
\text { use of SNSs }\end{array}$ \\
\hline
\end{tabular}

Table 7. Tests of Hypotheses

\begin{tabular}{lllll}
\hline Hypothesis & $\mathrm{r}$ & $\mathrm{p}$ & Relationship & Correlation \\
\hline H1: Privacy and Security Measures (Settings for protection) & 0.4984 & 0.000 & Yes & Medium \\
H2: Privacy and Security Measures (Viewers of profile) & 0.1838 & 0.000 & Yes & Small \\
H3: Legal and Acceptable Activities & 0.3997 & 0.000 & Yes & Medium \\
H4: Suspect Information & 0.2560 & 0.000 & Yes & Small \\
H5: Personal and Professional Time & 0.2273 & 0.000 & Yes & Small \\
H6: Professional and Ethical Behaviour (Content) & 0.2008 & 0.000 & Yes & Small \\
H7: Professional and Ethical Behaviour (Behaviour) & -0.0391 & 0.344 & No relationship (p $>0.05)$ & - \\
H8: Technical Experience & 0.0658 & 0.111 & No relationship $(p>0.05)$ & - \\
H9: Positive Attitude & 0.2449 & 0.000 & Yes & Small \\
H10: Usability (Technical Capacity, Ease of use, Functionality) & 0.5869 & 0.000 & Yes & Large \\
H11: Current and Controversial Issues (Discovery and Discussion) & 0.3668 & 0.000 & Yes & Medium
\end{tabular}

- A relationship exists between Suspect Information and successful use of SNSs. The correlation level is, however, small, meaning that checking information posted by an individual or others on SNSs does not influence greatly the successful use of SNSs.

- A relationship exists between Personal and Professional Time and successful use of SNSs. The correlation level is, however, small, meaning that limited distinction is made between use of Facebook professionally and personally and does not influence greatly the successful use of SNSs.

- A relationship exists between Professional and Ethical Behaviour (Content) and successful use of SNSs. The correlation level is, however, small, meaning that content of the profile does not greatly influence the successful use of SNSs.

- A relationship does not exist between Professional and Ethical Behaviour (Behaviour) and successful use of SNSs. 
Number of Facebook friends, swearing and commenting on photographs of bad behaviour is not associated with successful use of SNSs.

- A relationship does not exist between Technical Experience and successful use of SNSs. Levels of computer skills are not associated with successful use of SNSs.

- A relationship exists between Positive Attitude and successful use of SNSs. The correlation level is, however, small, meaning that the length of time and when SNSs are used does not greatly influence the successful use of SNSs.

- A relationship exists between Usability (Technical Capacity, Ease of use, Functionality) and successful use of SNSs. The correlation level is large, meaning that a fast Internet connection to an SNS that is easy to use, quick to learn and offering new and useful features greatly influences the successful use of SNSs.

- A relationship exists between Current and Controversial Issues (Discovery and Discussion) and successful use of SNSs. The correlation level is medium, meaning that the need to be alert to and engage in current and controversial issues does influence the successful use of SNSs.

\section{FINAL FACTORS FOR SUCCESSFUL USE OF SNSS}

The research indicates that the successful use of SNSs is predicated on a number of factors, not all of which contribute to the same extent. Successful use of SNSs is based principally on:

1. Usability: a fast Internet connection to an SNS that is easy to use, quick to learn and offering new and useful features

Of lesser import, but significant in the successful use of SNSs are:

2. Privacy and Security Measures (settings for protection): appropriate SNS settings to ensure that information is safe, and that they are aware of who can view their profile

3. Legal and Acceptable Activities: consideration of the effect of information on SNSs and ensure that they follow social contracts by practicing only legally and acceptable activities on SNSs

4. Current and Controversial Issues: the discovery and discussion of current and controversial issues on SNSs so as to use SNSs for learning, critical thinking and advising others

Of even lesser import, but contributing in a small way none the less to the successful use of SNSs are:

5. Privacy and Security Measures (viewers of profile): an appreciation/awareness of who is likely to view profiles on SNSs

6. Suspect Information: careful checking of information before it is posted to ensure accuracy and reliability, as well as checking other peoples' information so that they are not misled by anything read on SNSs

7. Personal and Professional Time: a separation of personal and professional activities on SNSs to ensure that work is complete before social activities occur

8. Professional and Ethical Behaviour (Content): a variety of information, inclusive of personal information, is posted that will not have embarrassing or other similar implications

9. Positive Attitude: extensive use of SNSs throughout the week and weekend to down/upload information which reflects a positive attitude towards the use of SNSs and other users
The research also indicates that the successful use of SNSs is measured by the extent to which: a range of content is available for viewing on a profile; SNSs are used to explore the profiles of people in whom users are interested; the behaviour of users includes looking at strangers' profiles (and vice versa), stalking and being defriended; the terms of use of SNSs are known and followed; professional work is completed before personal activities undertaken; information on SNSs is analysed critically and accurate information is displayed; a variety of users are active on SNSs each using SNS differently; users collaborate and engage each other on current and controversial issues; a sense of well-being and connectedness is derived from use of SNSs; and SNSs are used to interact with peers and lecturers and entities in the academy, for example, the library.

Finally, it should be noted that the research focused on the use of Facebook in a higher education setting. Whilst the results are not generalisable to other SNSs and contexts, the results do serve as useful research pointers.

\section{CONCLUSION}

SNSs are popular online destinations that offer students, lecturers, teachers, parents and businesses easy ways to build and maintain their relationships with each other. This research explored the use of Facebook in educational institutions culminating in the production of a set of factors for successful use of SNSs in such educational institutions.

SNSs can be used productively and to great advantage, but can also pose a significant threat to users if used without circumspection. The set of factors attempt to craft a use of SNSs that exploits the positive characteristics, whilst at the same time mitigating the negative characteristics. In an educational context, SNSs hold great promise.

This research focused on the use of specifically Facebook in an educational setting. Future work could usefully explore the use of Facebook in different settings (for example, schools, other universities) and the use of different tools (for example, flickr, MySpace) in educational settings. The applicability of the factors in a business setting could also be explored.

\section{REFERENCES}

[1] Agarwal, S. and Mital, M. (2009) 'An exploratory study of Indian university students' use of social networking web sites: implications for the workplace', Business Communication Quarterly, March, pp105-110.

[2] Anderson, R.L. (2010) 'Analysis of Social Network Sites and Supporting Functions', In: Proceedings of ASIST 2010, October 22-27, 2010, Pittsburgh, PA, USA.

[3] Berg, J, Berquam, L and Christoph, K (2007) 'Social Networking Technologies: a "Poke" for Campus Services', Educause Review. March/April, pp 32-44.

[4] Berson, I.R., and Berson, M.J. (2003) 'Digital Literacy for Effective Citizenship', Social Education, vol. 67, no. 3 , pp 164-167.

[5] Blackboard (2011) [online] Available at: http://www.blackboard.com (31 May 2011)

[6] Boyd, D.M., and Ellison, N.B. (2008) 'Social Network Sites: Definition, History, and Scholarship', Journal of Computer-Mediated Communication, vol 13, pp 210230.

[7] Bradley, A. (2007) Key Issues in the Enterprise Application of Web 2.0 Practices, Technologies, 
Products and Services, 2007, Gartner Group, 14 June, ID Number: G00148544.

[8] Christensen, R. (2002) 'Effects of Technology Integration Education on the Attitudes of Teachers and Students' Journal of Research on Technology in Education, vol. 34, no. 4, pp 411-433.

[9] Cloete, S., De Villiers, C. And Roodt, S. (2009) 'Facebook as an academic tool for ICT lecturers', In: Proceedings of SACLA '09, 29 June - 1 July, Mpekweni Beach Resort, South Africa, pp 16-22.

[10] Clyde, L.A. (2005) 'Educational Blogging', Teacher Librarian, vol. 32, no. 3, pp 43-45.

[11] Connell, T.H. (1994) 'The Internet: educational issues Libraries and the Internet: Education, Practice \& Policy, Library Trends. [online] Available at: http://findarticles.com/p/articles/mi_m1387/is_n4_v42/ai 15682168 (29 November 2008)

[12] Conole, G., Galley, R. And Culver, J. (2011) 'Frameworks for Understanding the Nature of Interactions, Networking, and Community in a Social Networking Site for Academic Practice', International Review of Research in Open and Distance Learning, vol. 12 , no. 3 .

[13] Czaja, S.J., Fisk, A.D., Hertzog, C., Rogers, W.A., Charness, N., Nair, S.N., and Sharit, J. (2006) 'Factors Predicting the Use of Technology: Findings From the Centre for Research and Education on Aging and Technology Enhancement (CREATE)', Psychology and Aging, vol. 21, no. 2, pp 333-352.

[14] Desisto, R.P., and Smith, D.M. (2008) Combining Social Networks with Business SaaS Offerings, Gartner Group, 12 February, ID Number: G00155092.

[15] Dimicco, J. M and Millen, D.R (2007) Identity Management: Multiple Presentations of Self in Facebook, In: Proceedings of the 2007 International ACM Conference on Supporting Group Work, Sanibel Island, Florida, USA. 4-7 November. pp 383-386.

[16] Dwyer, C., Hiltz, S.R., and Passerini, K. (2007) Trust and privacy concern within social networking sites: A comparison of Facebook and MySpace. In: Proceedings of the Thirteenth Americas Conference on Information Systems, Keystone, Colorado. 9-12 August.

[17] Ellison, N.B., Steinfield, C., and Lampe, C. (2007) 'The Benefits of FaceBook "Friends:" Social Capital and College Students' Use of Online Social Network Sites', Journal of Computer-Mediated Communication, vol. 12, pp 1143-1168.

[18] Facebook. (2007) Terms of Use, Facebook. [online] Available at: http://www.facebook.com/terms.php (29 November 2008)

[19] Greenhow, C. and Robelia, B. (2009) 'Informal learning and identity formation in online social networks', Learning, Media and Technology, vol. 34, no. 2, pp 119 140.

[20] Gross, R., and Acquisti, A. (2005) Information Revelation and Privacy in Online Social Networks (The Facebook case). In: Proceedings of the ACM Workshop on Privacy in the Electric Society (WPES), pp 71-80.

[21] Hair, J.F., Anderson, R.E., Tatham, R.L., and Black, W.C. (2009) Multivariate Data Analysis, $7^{\text {th }}$ Edition, Prentice Hall, Upper Saddle River, New Jersey.

[22] Haugen, M. (2007) Life's Better Together: A Look at Social Networking and Creating a Successful Internet Based Social Networking Service. Colligo. [online] Available at: http://www.micsymposium.org/mics_2007/papers/Hauge n.pdf (29 November 2008)
[23] Hewitt, A., and Forte, A. (2006) Crossing Boundaries: Identity Management and Student/Faculty Relationships on the Facebook, In: Proceeding of Computer Supported Cooperative Work, Banff, Alberta, Canada, 4-8 November.

[24] Hiltz, S.R and Turoff, M (2005) 'Education Goes Digital: The Evolution of Online Learning and the Revolution in Higher Education', Communications of the ACM, vol. 48, no. 10 , pp 59-63.

[25] Houghton, D.J. and Joinson, A.N. (2010) 'Privacy, Social Network Sites, and Social Relations', Journal of Technology in Human Services, vol. 28, pp 74-94.

[26] Hung, H-T. and Yeun, S.C-Y. (2010) 'Educational use of social networking technology in higher education', Teaching in Higher Education, vol. 15, no. 6, pp 703714

[27] IBM Corporation (2007) "Getting into" social software, IBM Corporation. [online]. Available at: http://www306.ibm.com/software/lotus/news/social_software.html. (25 February 2008)

[28] Kite, S.L., Gable, R, and Filippelli, L. (2010) 'Assessing Middle School Students' Knowledge of Conduct and Consequences and their Behaviors Regarding the Use of Social Networking Sites', The Clearing House, vol. 83, pp 158-163.

[29] Krieglstein, T. (2008) Faculty Ethics on Facebook - The Collaborative Project, Facebook Ethics. [online] Available at:

http://feeds.feedburner.com/ r/ActivitiesAndAffairsOne ForAll/ 3/213627105/faculty-ethics.html (28 November 2008)

[30] Khun, T.S. (1961) 'The Function of Measurement in Modern Physical Science', Isis, vol, 52, pp 161-193.

[31] Lawler, J.P. and Molluzzo, J.C. (2011) 'A Survey of First-Year College Student Perceptions of Privacy in Social Networking', Journal of Computing Sciences in Colleges, vol. 26, no.3, pp 36-41.

[32] Lih, A (2004) Wikipedia as Participatory Journalism: Reliable Sources? Metrics for evaluating collaborative media as a news resource, In: Proceeding of the 5th International Symposium on Online Journalism, University of Texas at Austin, 16-17 April.

[33] Lipka, S. (2007) 'For Professors, "Friending can be Fraught", Chronicle of Higher Education, vol. 54, no. 15 , pp A1-A28.

[34] Livingstone. S. and Brake, D.R. (2010) 'On the Rapid Rise of Social Networking Sites: New Findings and Policy Implications', Children \& Society, vol. 24, pp. 75-83.

[35] Lundy, J and Drakos, N (2007) How to Use Social Software to Support Your Learning Ecosystem, Gartner Group, 12 October, ID Number: G00152296.

[36] Mack, D., Behler, A., Roberts, A., and Rimland, E. (2007) 'Reaching Students with Facebook: Data and Best Practices', Electronic Journal of Academic and Special Librarianship, vol. 8, no. 2.

[37] Mann, J. (2008) Four Lessons Enterprises can Learn from Consumer Social Software, Gartner Group, 1 February, ID Number: G00154796.

[38] Martins, F.O.M., and Oliveira, T. (2008) 'Determinants of Information Technology Diffusion: a Study at the Firm Level for Portugal', The Electronic Journal of Information Systems Evaluation, vol. 11, no. 1, pp 27-34.

[39] Mathews, B.S. (2006) 'Do you Facebook? Networking with students online', Association of College and Research Libraries, vol.67, no.5. May. [online] Available at: 
http://www.ala.org/ala/acrl/acrlpubs/crlnews/backissues2 006/may06/facebook.cfm (28 November 2008)

[40] Mazer, J.P., Murphy, R.E., and Simonds, C.J. (2007) 'I'll See You On "Facebook": The Effects of ComputerMediated Teacher Self-Disclosure on Student Motivation, Affective Learning, and Classroom Climate', Communication Education, vol. 56, no. 1, pp 1-17.

[41] McLoughlin, C. and M. J. W. Lee (2008) "Mapping the digital terrain: New media and social software as catalysts for pedagogical change," in Hello! Where are you in the landscape of educational technology? In: Proceedings ascilite, Melbourne.

[42] McCracken, H. (2008) 'The Three Immutable Laws of Online Privacy', PC World, vol. 8, no. 2, p 13.

[43] Parameswaran, M., and Whinston, A.B. (2007a) 'Research Issues in Social Computing', Journal of the Association for Information Systems, vol. 8, no. 6, pp 336-350.

[44] Parameswaran, M., and Whinston, A.B. (2007b) 'Social Computing: An Overview', Communications of the Association for Information Systems, vol. 19, pp 762780.

[45] Prentice, B. (2007) Three Potential Pitfalls of Corporate Social Networking, Gartner Group, 4 December, ID Number: G00153423.

[46] Rimmer, I. (2007) 'Social Networking', $i$ Week, no. 115, 13 September, pp 15-18.

[47] Rozwell, C. (2008) Social Software Tools Give Researchers New Ways to Collaborate, Gartner Group, 1 February, ID Number: G00154917.

[48] Scialdone, M.J, Rotolo, A.J. and Snyder, J. (2011) 'Social Media Futures: Why iSchools Should Care', In: Proceedings of iConference 2011, February 8-11, 2011, Seattle, WA, USA, pp 514-521.

[49] Shipley, C. (2005) 'Your reputation precedes you', Network World, vol. 22, no. 22, p 37.

[50] Smith, D.M and Lundy, J (2007) Presence in Social Networks and Online Communities, Gartner Group, 14 May, ID Number: G00148172.
[51] Snyder, J., Carpenter, D., and Slauson, G.J. (2007) 'MySpace.com - A Social Networking Site and Social Contract Theory', Information Systems Education Journal, vol. 5, no. 2, pp 3-11.

[52] Statsoft (2008) Principle Components and Factor Analysis, Statsoft. [online]. Available at: http://www.statsoft.com/textbook/stathome.html (5 October 2008)

[53] Tam, L.Y.K. (2001) 'The Critical Success Factors that Influence Organisations to Adopt Internet Technology', Malaysian Journal of Library \& Information Science, vol. 6 , no. 2 , pp 35-51.

[54] Tapscott, D and Williams, A.D (2007) 'The Wiki Workplace', Business Week Online, 26 March, p 15.

[55] Tebbutt, D. (2005) 'Making the Right Connections', Information World Review, no. 224, pp 19-21.

[56] Tebbutt, D (2006a) 'Genie in a Bottle', Information World Review, no. 224, pp 19-21.

[57] Tebbutt, D (2006b) The IT manager's guide to social computing, The Register. [online] Available at: http://www.theregister.co.uk/2006/07/21/it_managers_gu ide_to_social_computing (23 October 2007)

[58] Tuffley, D. (2007) Email Etiquette (Netiquette), Griffith University. [online] Available at: http://www.cit.gu.edu.au/ davidt/email_etiquette.htm (28 November 2008)

[59] Valdes, R. (2007) Facebook and the Emerging Social Platform Wars, Gartner Group, 17 October, ID Number: G00152268.

[60] Walls, A. (2007) Corporate Use of Social Networks Requires Multilayered Security Control, Gartner Group, 28 November, ID Number: G00153595.

[61] Yap, R., Muirhead, B., and Keefer, J. (2005) 'Blog RUBRIC: Designing your Business Blog', International Journal of Instructional Technology and Distance Learning, vol. 2, no. 11, pp 53-59. 